\title{
Learners and System Readiness for Digital Learning in Ethiopian Health Sector: The Path to Blended Learning
}

Yifru Berhan ( $\nabla$ yifruberhanm@gmail.com )

St Paul's Hospital Millennium Medical College https://orcid.org/0000-0002-3779-0718

\section{Muluken Dessalegn}

Amref health Africa in Ethiopia

\section{Aranka Hetyey}

Amref flying doctors in the Netherlands

\section{Bekalu Assamnew}

Amref Health Africa in Ethiopia

\section{Sentayehu Tsegaye}

Amref health Africa in Ethiopia

\section{Misrak Makonnen}

Amref health Africa in Ethiopia

\section{Sintayehu Abebe}

Amref health Africa in Ethiopia

\section{Research}

Keywords: blended learning, digital Learning, Ethiopia, face-to-face learning, lower and mid-level health workers, quantitative and qualitative study

Posted Date: August 24th, 2021

DOl: https://doi.org/10.21203/rs.3.rs-820709/v1

License: (a) (1) This work is licensed under a Creative Commons Attribution 4.0 International License. Read Full License 


\section{Abstract}

\section{Background}

In Ethiopia, the traditional face-to-face learning method is still the predominant modality to formally educate and train health workers in many universities and colleges, but could not alleviate the critical national shortage of health workforce. The increasing global digital interconnectedness, the emerging user-friendly and cost-effective digital learning platforms are easing the barriers for reaching unlimited audience, and the lessons learned from coronavirus disease (COVID-19) restrictions have opened room for digital learning. Therefore, the purpose of this study was to get an insight into the learners and system readiness for digital learning scale up.

Methods

Quantitative and qualitative methods were employed by including 393 lower and mid-level health workers from regional states and Addis Ababa city, and 27 key informants from different governmental and nongovernmental organizations. The market appetite for digital learning, willingness to pay, use of the mobile devices, delivery mode preference, and the current context pertinent to digital learning were assessed.

Results

Almost all of the study participants possessed mobile phones, and the majority (92\%) had smartphones. Most of those who had digital learning experience agreed or strongly agreed with digital learning is costeffective (88.7\%), most effective and efficient (90.3\%) with no geographic limitation (95.2\%), easier to use (91.9\%), and enabling the required skills and knowledge (89\%) as compared to face-to-face learning, which were also supported by key informants. More than $90 \%$ of survey participants with digital learning experience regarded classroom learning as more expensive than digital learning and the majority were willing to pay for digital learning service, which was also echoed by key informants. The most preferred delivery mode was blended learning.

\section{Conclusion}

Study participants have expressed their optimism towards digital learning, most preferably through a blended delivery mode. The cost-effectiveness of the method, high access to mobile devices, government and partners' commitment along with trainees preference are persuasive conditions to implement and transform digital learning for health workers in Ethiopia and increase the health workforce as an important intervention for achieving universal health coverage and health-specific sustainable development goals at large.

\section{Introduction}

As virtual communication has elevated the personal interaction over the decades, digital learning is also on the horizon for making progress in both formal education and in-service training globally. ${ }^{1,2}$ On top of 
the increasing digital interconnectedness, the emerging user-friendly and cost-effective digital learning platforms are easing the barriers for reaching unlimited audience at a distance for many of the academic activities, including health training. Further, the broad range of information what a digital landscape provides to learners and its online accessibility unless otherwise restricted enables it to get a larger audience worldwide. That is why complementing learning through an electronic platform is becoming an alternative and probably the most preferred method of learning and information exchange platform by the generation of the new millennium. . $^{3,4}$

As the speed of digital technologies in making information available from a large collection is extraordinary, it is recognized as a very good platform for eventually transforming information into knowledge. This is probably one of the reasons why many of the new millennium learners get attracted to it. ${ }^{5}$ It is predicted that the global digital learning market by 2026 will be twice of the 2020 estimate, with an absolute growth of $110 \%$, mainly as a result of continuous growth of blended learning, mobile $(\mathrm{m})$ learning, advancing virtual reality and augmented reality applications, eventually increasing the market need for skills in digital learning, and the ongoing digital transformation in delivering in-service training. 6,7 In the global context, it is predicted that virtual reality (including virtual patient) and augmented reality applications may soon revolutionize the learning modality in health education, including basic science and clinical medical education, and learning the basic surgical skills, as the 360-degree videos and virtual anatomy are already developed to train future health workers. ${ }^{8}$ Whether the Ethiopian education and training modality will catch up the global move or not is with wide uncertainty.

The COVID-19 pandemic inflicting schools closure and lockdown in many countries has propelled the demand for virtual meetings and digital learning, which is considered as a live experiment for its global application in the academics, ${ }^{9}$ a 'blessing in disguise'. It is also reported that students in higher education institutions are highly demanding for digital courses, digital learning materials, and paid subscriptions. ${ }^{10}$ Largely, the inclination towards the use of digital learning is globally growing. However, digital learning may not be without limitation; among others, there is a concern of losing the opportunity of socialization and collegial learning, leading to a crisis of the vertical transmission of school culture and the increase of horizontal socialization among young people. ${ }^{5}$ The poor Internet connectivity and lack of access in lowincome countries are big challenges.

Short of that, the rapid advancement of information and communication technology (ICT), artificial intelligence, and e-health and $\mathrm{m}$-health initiatives are continuously influencing the models of healthcare and health systems management globally. Thus, the challenges related to training and education of healthcare workers can be withstood by applying contemporary solution, including digital learning, particularly in resource constrained settings. ${ }^{7,11}$ The World Health Organization and other authors have identified potential impacts of the digital learning for health workers as it increases the enrolment capacity, removes geographic and time barriers, improves efficiency and learning outcomes, and fosters interpersonal learning and gender balancing. ${ }^{7,12-14}$ 
Specific to Ethiopia, where the current total population is estimated at 117 million and the shortage of health workforce is big with low density ( 0.7 per 1000 population, more than 3-fold lower than the minimum threshold of 2.3), ${ }^{15}$ demanding over 30,000 annual productions to achieve universal health coverage by 2030 (the current capacity is 10,000 per annum). This may not be materialized in the years to come with the traditional method of education delivery unless an innovative approach is implemented, particularly for upgrading the health extension workers.

In many high-and middle-income countries, digital learning is part of the mainstream in medical education for decades; ${ }^{16}$ however, little is done and known about its application and implication in lowincome countries, including Ethiopia. The digital learning experience presented in Table 1 shows some of the efforts that development partners have attempted to introduce it as one of the training modalities.

Therefore, the purpose of this study was to get an insight into the learner and system readiness for digital learning in this country where computers, tablets, and broadband Internet connections are not readily and widely available, and the national shortage of health workforce is critical.

Table 1. Digital learning experience in Ethiopia involving health extension workers, midwives, and nurses as trainees, 2021.

\begin{tabular}{|llll|}
\hline & & \multicolumn{2}{c|}{ Number of trainees } \\
Implementer & Delivery Method & HEW & Other $^{\mathrm{n}}$ \\
\hline Last Miles Health & Online/mobile & 5,000 & \\
\hline UNFPA Ethiopia & Blended & & 767 \\
\hline JSI Ethiopia** & Blended & 6,215 & 75,000 \\
\hline PEPFAR & Blended & & 1,520 \\
\hline Oppiamobile & Blended & 157 & \\
\hline Amref Ethiopia & Blended & 23,654 & 1,865 \\
\hline REACH Ethiopia & Online/mobile & 57 & 68 \\
\hline Jhpiego Ethiopia & Blended & & 99 \\
\hline
\end{tabular}

Includes Nurses, Midwives, Health development team members, supervisors, other health workers.

*HEW $=$ Health extension worker. ${ }^{*} \mathrm{JSI}$ research and training institute.

Table 2. Internet connectivity status of health extension workers, midwives, and nurses, Ethiopia, 2021. 


\begin{tabular}{|lll|}
\hline Indicator & & Percentage \\
\hline Access to Internet & 91.1 \\
\hline Internet type at workplace & Mobile data & 84.4 \\
\cline { 2 - 3 } & Wireless & 12.6 \\
\cline { 2 - 3 } Internet type at home & Broadband & 0.5 \\
\cline { 2 - 3 } & Other & 2.5 \\
\hline Where do you access Internet & Mobile data & 94.4 \\
\cline { 2 - 3 } & Wireless & 4.7 \\
\cline { 2 - 3 } & Broadband & 0.3 \\
\cline { 2 - 3 } & Other & 0.6 \\
\cline { 2 - 3 } & Home & 72.6 \\
\hline Office & 9.0 \\
\hline Cyber cafe & 0.5 \\
\hline How often do you use Internet & Other & 17.9 \\
\hline & Daily & 71.2 \\
\hline Every other day & 19.8 \\
\hline Weekly & 3.4 \\
\hline & Occasionally & 5.6 \\
\hline & & \\
\hline
\end{tabular}

\section{Methods}

\section{Methods}

\section{Study design and study population:}

Quantitative and qualitative methods were employed by including mid-level and lower health workers and key informants of stakeholders. The study remitted its scope to three regional states (Afar, Amhara, and SNNP) and Addis Ababa city administration for the quantitative survey, and the respondents were health extension workers (low level), nurses and midwives (mid-level). Key informants for the in depth interview were government and development partner employees working in the health sector and residing in Addis Ababa and big towns. The survey was conducted from January to February 2021.

\section{Sample size and sampling:}


To the researchers' knowledge, as there was no study for the stated objective, the sample size was determined by computing the minimum sample size required for accuracy in estimating proportions by considering the standard normal deviation set at $95 \%$ confidence level, $50 \%$ proportion, and 0.05 margin of error, which resulted in a total sample size of 384 . With the assumption of $5 \%$ non-response, the total sample size was initially planned to be 403 , but the turnout was 393 (98\%). The sample was proportionally allocated based on the size of the population in the study areas. The qualitative data collection included stakeholders as key informants from health science colleges, regional health bureaus, Ministry of Health (MOH), and non-governmental organizations (NGO). A total of 27 key informants from government and development partner employees working in the health sector were interviewed to substantiate the quantitative result (Annex 1).

\section{Data collection:}

The data collectors were given hands on training on the data collection tool, interviewing techniques, the client's field survey policy, and conducting survey by applying precautionary measures amid Covid-19 pandemic. Pretested questionnaire for the survey and guiding questions for the qualitative study were used. Learners attitude towards digital learning, digital learning experience, use of mobile device, delivery mode preference, and the current context pertinent to digital learning were included in the questionnaire.

\section{Data quality assurance:}

To ensure the standards of the data collection process and ultimately ensure the reliability of the data collected, the following four main strategies were employed: first, all filled questionnaires were checked by the supervisors daily and centrally administered by the data manager. Second, there were instances of random back-checking of data collectors' work by the field supervisor to make sure that the quality of the data was not compromised. Third, the supervisors were also checking all the filled questionnaires and interview results on the spot at the field level.

\section{Data analysis:}

Quantitative data are presented in tables and graphs. A hybrid coding approach, which includes the process of creating pre-set and emergent codes, was used to analyze the qualitative data; it was transcribed, compiled, and analyzed. Thematic analysis was employed to analyze the qualitative data.

\section{Results}

\section{Sociodemographic characteristics}

More than three-fourths of the study participants (75.3\%) were females, and most were working in health centers $(85 \%)$, married $(75.8 \%)$, and from urban areas $(58.8 \%)$. The level of education of the majority of respondents was either bachelor's degree holder (38.9\%) or level IV diploma (53.7\%). The mean age was 29.4 years. The average work experience of the respondents was 7.5 years with 4.6 years in the current facility. 


\section{Experience and readiness of study participants for digital learning}

With the exception of one study participant, all possessed mobile phones as presented in Fig. 1. Of which, $92 \%$ were having smart phone. Alternative digital devices like desktop, laptop, and tablet were owned by $13.5 \%, 7.9 \%$, and $0.5 \%$ of the study participants, respectively. Most of the participants $(36.7 \%)$ indicated that they used mobile phone for more than 10 years; $31.8 \%$ used for $6-10$ years and the remaining $31.5 \%$ used for less than 6 years.

Key informants from $\mathrm{MOH}$ and Last Miles Health shared with us their observation and concern about the healthcare workers' competence on utilization of mobile devices for digital learning. They said owning smart phone or computer may not ensure readiness to utilize it as a learning device. A key informant from Last Mile Health has voiced the skill gap of some of the health workers in the utilization of computers and mobile devices. Similarly, a key informant from $\mathrm{MOH}$ expressed his concern on utilization of the digital technologies.

".... there are serious problems in utilization of mobile devices at hand by the healthcare workers. Some of them have latest iPhone and Android phones but when we ask them to attend trainings, they usually say they cannot make that due to lack of desktops or laptops. They do not exactly know working with their phones. There are skill gaps in proper utilization of the technology devices. There is a need to give basic training on how to use their phones or computers for digital learning. It requires some effort to make the healthcare workers ready for digital learning". [Key informant from $\mathrm{MOH}$ ].

Analysis of the healthcare workers survey also showed that more than half $(55.2 \%)$ have heard about digital learning ( $65.6 \%$ of HEWs, $57.1 \%$ of midwives, and $47 \%$ of nurses), but had little experience and information prior to the COVID-19 pandemic. Key informants from different Health Science Colleges outside Addis Ababa and development partners indicated that they never had such considerable experience with digital learning prior to the Covid-19 pandemic.

"To be honest, the concept of digital learning was accentuated during Covid-19 when we were left with no option of providing courses on a face-to-face modality. It (digital learning) just came as the best solution to continue the teaching learning process which was interrupted due to the pandemic. We didn't have substantial experience about digital learning before the pandemic". [Key informant from Arba Minch Health Science College]

"Covid-19 is like a wake-up call to digitize the education sector. It showed us the need for online education in Ethiopia, which has been neglected for long".

[Key informant from Minister of Science and Higher education]

As shown in Table 2, most of the respondents had access to internet (91.1\%), mainly using mobile data $(94.41 \%)$ with daily internet access $(71.23 \%)$ and at home (72.63\%). The majority $(71.2 \%)$ uses Internet 
on daily basis.

\section{Perception of study participants about digital learning}

Sixty-two of the study participants had the experience of learning through digital learning. The majority of these respondents $(87.1 \%)$ indicated that they took one to five courses with digital learning, and most of them (69.4\%) attended the training while they were at home, mainly during and about the Covid-19 pandemic. As shown in Fig. 2, most of them agreed or strongly agreed as digital learning is most effective and efficient to give a quick job aid (90.3\%) and time freedom (93.6\%) as compared to face-toface learning.

The majority also agreed or strongly agreed on no geographic limitation for digital learning (95.2\%), its cost effectiveness (88.7\%), a quicker method of getting feedback in learning (58.1\%), better to improve the knowledge and skills (64.5\%), easier to use (91.9\%), and giving more space to complete different types of courses (77.4\%). Nearly $89 \%$ of them perceived that they had the required skills and knowledge after participating in digital learning.

However, most of these respondents expressed their reservation about the amount of interaction on digital learning to satisfy learners and learning objectives; only about $41 \%$ of the respondents agreed or strongly agreed that digital learning was interactive to satisfy learning objectives.

Consistent with this, a key informant from one of the development partners shared his experience on the effect of their M4Youth project brought about as benefits and the identified gaps as follows.

"The m-health has helped us provide sexual and reproductive health information to university students at Adama Science and Technology University via SMS. In the process, we realized that students could not easily communicate whenever they face some difficulties. Information flow was from our side only". [Key respondent from NGO partner]

With regard to their preference for future training, $62.9 \%, 25.8 \%$, and $11.3 \%$ preferred blended, digital alone, and face-to-face type of learning, respectively. In depth interview participants also preferred a blended type of learning approach.

"Digital learning is preferred to provide foundation trainings, but it is not easy to use it alone for trainings that require intensive and direct practical sessions. For instance, it is quite difficult to offer Basic Emergency Obstetric Care (BEMOC) training to health workers only using digital learning. It should be supplemented by face-to-face training". [Key informant from $\mathrm{MOH}$ ].

\section{Perception of study participants about the cost of digital learning}

As shown in Fig. 2, most of the respondents with digital learning experience indicated that it was more cost-effective than the traditional face-to-face learning. More than $90 \%$ of them indicated classroom learning was more expensive than digital learning. They also perceived that internet cost for digital 
learning was reasonable. The key informants' perception was also consistent with the survey participants. Twenty-two key informants indicated that digital learning was more cost-effective than the traditional face-to-face learning; the others were either indifferent or preferred blended approach in terms of cost-effectiveness.

“...Digital learning has paramount importance in saving the costs associated with transportation, accommodation, training venue/hall rent, food, printing, duplication, and per diem, and the other related costs". Key informant from Addis Ababa University

"Digital learning is costlier than the traditional learning in the beginning but the cost decreases when it starts operating as compared to the traditional classroom learning. Digital learning has seemingly higher initial investment, but the recurrent costs are smaller than the traditional one". [Key informant from NGO partner]

Similarly, a key informant from $\mathrm{MOH}$ stated:

“... we can provide trainings for many participants without a significant cost and effort change. Increasing number of students means increasing cost for the traditional/face-to-face modality. It requires additional class and instructors. But the incremental costs of courses through digital solutions increases at a far slower rate than face-to-face modality. Digital learning is easily scalable. It enables the providers to produce the materials once and share with as many students as needed'. Key informant from $\mathrm{MOH}$

Key informant from Ethiopian Midwives Association endorsed the cost-effectiveness of digital learning by stating that it creates the opportunity to reach a large number of health professional with limited resource, as they have human and financial constraints to reach to more than 17,000 midwives in the country.

\section{Willingness to pay for digital learning}

A considerable portion (50\%) of the sample healthcare workers and key informants expressed their willingness to pay for digital learning. Half of the survey respondents who participated on digital training in the past were willing to pay for it. Among them, $100 \%, 90.3 \%$ and $64.5 \%$, respectively, were willing to pay for Internet, registration, and course fee, on average \$8.7 USD per course with a minimum of $\$ 2.4$ and a maximum of $\$ 23.9$.

Eighteen of the total key informants were also willing to pay for digital learning, particularly to cover the costs associated with Internet and training. Regarding the amount, they indicated that the cost should vary with the type of module, the contents, and weight given to the module.

"...yes, we are willing to cover module fee, but we could not now decide the amount per module. The amount depends on the types and importance of the modules". [Key informant from Addis Ababa Health Bureau].

\section{Costs to run digital learning}


Though the costs differ among organizations, most key informants mentioned costs for Internet and physical resources that are necessary to enable the use of data, computerized devices, methods, systems, and processes as critical to run the digital learning, without underestimating the cost for human resource in preparing and delivering teaching materials. Some key informants have emphasized the Internet cost as a big challenge.

"... Regarding the costs to run digital learning, Internet cost is more expensive than the other costs. We can use what we already have with the existing human resource and computer server". [Key informant from Addis Ababa Health Bureau].

\section{Concerns to scale up digital learning}

Some of the key informants expressed their concern with regard to the political instability of the country, on and off electric power failure, the technical capacity of trainees to operate digital technologies (ICT skills), and resistance towards new technology and new way of learning.

"Power shortage is holding us back from optimally providing digital learning to healthcare workers. We tried different options like solar panels to address the power problem, mainly in the remote rural areas, but it couldn't be addressed at all by our own effort. It requires participation and collaboration of different stakeholders". [Key respondent from NGO partner]

"Health professionals' awareness towards digital learning and use of devices need to be enhanced to rollout digital learning solutions. They should be aware that mobile phones can be used in the same way as a laptop, tablet or desktop". [Key respondent from NGO partner]

\section{Discussion}

This study has provided important insight on the feasibility of digital health learning in Ethiopia. The majority of the study participants had a positive attitude towards blended learning, and have expressed their readiness to pay a modest amount of money if asked to do so. The use of mobile phone by almost all of the study participants, the larger Internet connectivity with their mobile, and the high interest in digital learning among those who had the experience may indicate the competitive and comparative advantage of digital learning in this digital era/information age. After an extensive literature review, the WHO has also noted the potential of digital learning to improve the competencies and satisfaction of health workers. However, its effectiveness and outcomes may be influenced by several factors, including the digital learning modality (mobile phones, online digital learning, virtual reality, or others), delivery mode (blended or fully digital) ${ }^{7}$, learner's characteristics (including self-regulated skills in operating and using applications) as one of the predictors for effectiveness of blended learning. ${ }^{17}$

Previous authors have as well noted that the unprecedented mobile service utilization and the increasing interconnectedness through Internet is opening room for the digital learning, and probably evolving to change the modality of future education. ${ }^{18}$ For low-income countries, earlier prediction by Poushter $\mathrm{J}$ was 
as "smartphone ownership and internet usage continues to climb in emerging economies", ${ }^{19}$ which is in line with the current finding. The rising demand for smart phone and mobile Internet users in Ethiopia (in $2020,41 \%$ of the population having mobile connection with $19 \%$ Internet connection) ${ }^{20,21}$ is encouraging to plan the m-learning for training and $\mathrm{m}$-health for the population at large. Local and international literature review has shown the potentially effective and financially scalable solutions to digitalize health workforce trainings, including m-learning and blended digital learning (with comparative advantages for both pre-and in-service trainings). ${ }^{7,11,22,23}$

However, as the key informants pointed out, the healthcare workers' ability to function with the electronic devices may be a critical factor. If they are not provided training on how to use their phones for digital learning purpose for those with limited skills, they may lag behind or drop the training. ${ }^{17}$ The frequent electric power interruptions, political turmoil, and the limited experience of higher educations in leveraging digital devices are key challenges for scaling up digital learning in Ethiopia.

Apart from the unaffordability of laptops/desktops and broadband by all, the high utilization of smartphone for Internet access by most of the study participants may be explained by its easier portability. Certainly, it was already noted that there is a growing interest and practice in smartphone to get access to Internet, even in the developed world, ${ }^{24}$ probably because of its easier access to operate and portability. In essence, apart from its day to day use for information exchange, the growing number and interest in using smartphone could be considered as a fertile ground for the m-health market (in a broader sense), as it enables delivering and receiving both formal (credited) and informal education.

The familiarity of the study participants with the mobile technology is another important indicator for the success of digital learning if gets implemented in larger scale; based on earlier studies, it was noted that a learner with difficulty of using the digital technology is likely to abandon it; develops negative attitude; and eventually fails to complete the course. ${ }^{25,26}$ Literature review has also shown that health professional skills are better improved with m-learning, virtual patients, and virtual reality than web-based learning. ${ }^{7}$

Like the majority of this study participants, the global tendency is to institutionalize digital learning by blending it with the traditional teaching-learning methods. In fact, in due course, the digital learning may substitute some of the traditional pedagogical approaches for health science education, including the didactic lecture (face-to-face and teacher-centered model) and patient-based learning, but may not fully fit for all practical/skill-based education, as hands on training is irreplaceable for the required skills acquisition, especially for health workers.

As learned from the revised national eHealth strategy, although currently the predominant modality of learning is the traditional face-to-face, digital learning has drawn the attention of the Government of Ethiopia as well as other stakeholders as one of the potentially effective methods to counter the gaps in both the quantity and quality of the health workforce. The cost-effectiveness of digital learning is what was emphasized by the study participants, which is in agreement with two studies findings in Ethiopia 
that compared the cost effectiveness of blended digital learning with face-to-face learning and found that the cost of digital learning was up to $50 \%$ less than the latter (the mean cost per trainee was $\$ 1,023$ and $\$ 1,648$ for the first study and $\$ 116.80$ and $\$ 235$ in the second study, respectively). ${ }^{27,28}$ Other studies from Nigeria and United States of America reported similar results. ${ }^{12,29}$

Recently, the COVID-19 pandemic has also further accelerated the momentum and demand for digital learning solutions in Ethiopia22,23,30 and globally. ${ }^{31}$ Further, as per the Ambient Insight Research report, Ethiopia showed a 20\% growth in self-paced eLearning rates between the year 2016 and 2021, indicating the potential of the market demand for digital learning. ${ }^{32}$

On top of enacting guidelines, policies, and strategies that favor implementation of digital learning, the government and development partners have suggested digital learning as potentially effective methods to help address the challenges; $7,33,34$ the shortage of health workers is worsening as the population size of Ethiopia is annually increasing by about 3.3 million. ${ }^{35}$ Nevertheless, the digital learning being less interactive is a concern not to revert the currently recommended student-centered teaching method to teacher-centered approach. As a mitigating strategy, while the repository in the digital devices mimics text and reference books, the virtual two-way interactions with instructors may mimic delivering courses in classroom. Therefore, in addition to uploading the course content and assessment questions, organizing some online interactive sessions may fill the observed gap and learners' inconvenience in the absence of classroom two-way communications.

In general, the data triangulation from different sources indicated the consistency and reliability of the gathered information. However, the study is not without limitations. Due to Covid-19 restriction, it was not possible to conduct focus group discussion. The study did not include other mid-level health professionals (like health officers, anesthetists, optometrists, radiographers, and laboratory technologists), who can benefit from similar undertaking.

\section{Conclusion}

Quantitative study triangulated with qualitative study has demonstrated the learners' readiness for blended digital learning by stating that it is a cost-effective, efficient method of learning, granting learners more time, and placing flexibility. Nearly three-fourths of the study participants (low-and mid-level health workers) had Internet access and $92 \%$ used smartphone. Study participants are optimistic about and volunteer to pay for blended digital learning The cost-effectiveness of the method, high access to mobile devices, government and partners' commitment are persuasive conditions to implement and transform digital learning in Ethiopia as a mitigating strategy for the critical shortage of the health workforce.

\section{Declarations}

The research proposal was approved by the Amref Ethiopia institutional review committee. As per the ethical standards of the National Public Institute of Ethiopia, informed verbal consent was taken from all 
participants prior to interview. All respondents were briefed about the purpose of the evaluation, the type of information required, the way the data would be handled and used, their rights during and after data collection as a participant. They were also given the opportunity to ask questions and understood that participation was voluntary, and they were free to withdraw from participation at any time, even after verbal consent was granted and interview started. All study participants were informed that identifiers will be omitted and data analyses will be done in aggregate to ensure confidentiality and anonymity.

As the study was conducted during covid-19 era, all the study enumerators and participants were required to wear facemask, use hand sanitizer, and keep physical distance of at least 2 meters to protect them and the study participates from COVID-19.

\section{Competing interests}

The authors declare that they have no competing interests.

\section{Funding}

Philips foundation supported this research.

\section{Authors' contributions}

$M D, A H$, and $B A$ originated the idea and performed the preliminary analysis and write up. YB reviewed literature, further analyzed the data and prepared the manuscript for publication. ST, MM, and SA reviewed and enriched the first draft and final report. All authors read and approved the final manuscript.

\section{Acknowledgement}

We would like to express our gratitude to Philips Foundation for funding the research.

\section{References}

1. Scherer R, Rohatgi A, Hatlevik OE. Students' profiles of ICT use: Identification, determinants, and relations to achievement in a computer and information literacy test. Comput Hum Behav. 2017; 70: 486-499.

2. Sun P-C, Tsai RJ, Finger G, Chen Y-Y, Yeh D. What drives a successful e-learning? An empirical investigation of the critical factors influencing learner satisfaction. Comput Educ. 2008; 50: 11831202.

3. Ansari JAN, Khan NA. Exploring the role of social media in collaborative learning the new domain of learning. Smart Learn Environ. 2020; 7: 9. Retrieved on July 5, 2021 from: https://doi.org/10.1186/s40561-020-00118-7

4. Dziuban C, Walker JD. ECAR Study of Undergraduate Students and Information Technology. 2012. Louisville: EDUCAUSE Centre for Applied Research. Retrieved on July 5, 2021 from: https://library.educause.edu/ 
5. Pedro F. The New Millennium Learners: Challenging our Views on Digital Technologies and Learning. Nordic Journal of Digital Literacy. 2008; 2(4):244-264

6. Research and Markets. Global E-learning Market - Outlook and Forecast 2021-2026. 2021. Retrieved on July 10, 2021 from: https://www.researchandmarkets.com/reports/5327504/global-e-learningmarket-outlook-and-forecast

7. WHO: Digital education for building health workforce capacity. In. Geneva, Switzerland: WHO; 2020.

8. Gleb B. Virtual reality versus augmented reality versus mixed reality. Difference and real-life applications. 2020. Retrieved on July 12, 2021 from: https://rubygarage.org/blog/differencebetween-ar-vr-mr

9. Research and Markets. E-learning Market - Global Outlook and Forecast 2020-2025. 2020. Retrieved on July 10, 2021 from: https://www.researchandmarkets.com/reports/5018693/e-learning-marketglobal-outlook-and-forecast

10. Research and Markets. Global E-learning Market Report 2021-2026: Paradigm Shift from Content Delivery to Interactive Learning Platforms. 2021. Retrieved on July 11, 2021 from: https://www. Global-E-learning-Market-Report-2021-2026-Paradigm-Shift-from-Content-Delivery-to-InteractiveLearning-Platforms.html

11. Frehywot S, Vovides Y, Talib Z, Mikhail N, Ross H, Wohltjen H, Bedada S, Korhumel K, Koumare AK, Scott J. E-learning in medical education in resource constrained low- and middle-income countries. Human resources for health. 2013; 11(1):4.

1. Sissine M, Segan R, Taylor M, Jefferson B, Borrelli A, Koehler M, Chelvayohan M: Cost Comparison Model: Blended eLearning versus traditional training of community health workers. Online J Public Health Inform. 2014; 6(3):e196-e196.

13. Berhe H, Dowling P, Nigatu W: Comparison of the cost effectiveness of pre-service training and inservice training in Ethiopia. J Pharm Policy Pract 2014, 7(Suppl 1):018-018.

14. USAID: A blended learning approach for basic emergency obstetric and newborn care (BEmONC) training in Ethiopia. 2016. Retrieved on July 9, 2021 from: https://pdf.usaid.gov/pdf_docs/pa00mx94.pdf

15. Ministry of Health of Ethiopia (MOH). Human resource. Retrieved on July 11, 2021 from: https://www.moh.gov.et.ejcc/index/humanresource

16. Ellaway R, Masters K. AMEE Guide 32: e-Learning in Medical Education. 2008. Retrieved on July 12, 2021 from: https://www.semanticscholar.org/paper/AMEE-Guide-32-e-Learning-in-medicaleducation-Part-Ellaway-Masters/

17. Kintu MJ, Zhu C, Kagambe E. Blended learning effectiveness: the relationship between student characteristics, design features and outcomes I J Edu Tech Higher Edu. 2017; 14:7.

18. Denton L. How digital learning is changing the future of education. 2021. Retrieved on July 14, 2021 from: https://www.emeraldgrouppublishing.com/how-digital-learning-changing-future-education 
19. Poushter J. Smartphone ownership and internet usage continues to climb in emerging economies. 2016. Retrieved on July 12, 2021

from: https://www.pewresearch.org/global/2016/02/22/smartphone-ownership-and-internet-usagecontinues-to-climb-in-emerging-economies/

20. Central Statistics Agency (CSA) [Ethiopia] and ICF International: Ethiopia demographic and health survey 2016. In. Addis Ababa, Ethiopia and Rockville, Maryland, USA: Central Statistical Agency (CSA) and ICF International; 2016.

21. Harding K, Biks GA, Adefris M, Loehr J, Gashaye KT, Tilahun B, Volynski M, Garg S, Abebaw Z, Dessie $K$ et al: A mobile health model supporting Ethiopia's eHealth strategy. Digit Med. 2018; 4(2):54-65.

22. Amref Health Africa. Leap. Retrieved on July 12, 2021

from: [https://elsevierfoundation.org/partnerships/health-innovation/amref-health-africa-leap/

23. Federal Ministry of Health of Ethiopia: "COVID-19 Ethiopia", a Mobile Learning Platform for Health Workers, is Launched. In. Addis Ababa: EMOH; 2020.

24. Anderson M, Horrigan JB. Smartphones help those without broadband get online, but don't necessary bridge the digital divide. 2016. July 12, 2021 retrieved from: http://www.pewresearch.org/facttank/2016/10/03/smartphones-help-those-without-broadband-get-online-but-dont-necessarily-bridgethe-digital-divide/.

25. Hofmann J. Solutions to the top 10 challenges of blended learning. Top 10 challenges of blended learning. 2014. Available on cedma-europe.org.

26. Oxford Group. Blended learning-current use, challenges and best practices. 2013. From http://www.kineo.com/m/0/blended-learning-report-202013

27. Manyazewal T, Marinucci F, Belay G, Tesfaye A, Kebede A, Tadesse Y, Lehman S, Temesgen Z: Implementation and Evaluation of a Blended Learning Course on Tuberculosis for Front-Line Health Care Professionals. Am J Clin Pathol 2017, 147(3):285-291.

28. Dejene D, Yigzaw T, Mengistu S, Ayalew F, Kahsaye M, Woldemariam D: Exploring health workforce regulation practices and gaps in Ethiopia: a national cross-sectional study. Global Health Research and Policy 2019, 4(1):36.

29. Bishop, T. Research Highlights: Cost Effectiveness of Online Education. Retrieved on July 5, 2021 from: http://www.sloanconsortium.org/publications/books/pdf/ce_summary.pdf

30. UNFPA: A rural training solution for health workers. In. New York, USA: UNFPA; 2016.

31. Dong C, Lee DW-C, Aw DC-W: Tips for medical educators on how to conduct effective online teaching in times of social distancing. Proceedings of Singapore Healthcare.

32. Docebo. Elearning market trends and forecast 2017-2021. Retrieved on July 6, 2021 from: [https://www.docebo.com/resource/elearning-market-trends-and-forecast-2017-2021/

33. Federal Ministry of Health of Ethiopia: Ethiopian national eHealth strategy 2015- 2020. In. Addis Ababa: FMOH; 2015. 
34. Federal Ministry of Health of Ethiopia: Revised human resource for health strategic plan in Ethiopia. In. Addis Ababa: Federal Ministry of Health of Ethiopia. 2015.

35. Worldometer. Ethiopia population 1950-2020. Accessed from: worldometers.info/world-population/

\section{Figures}

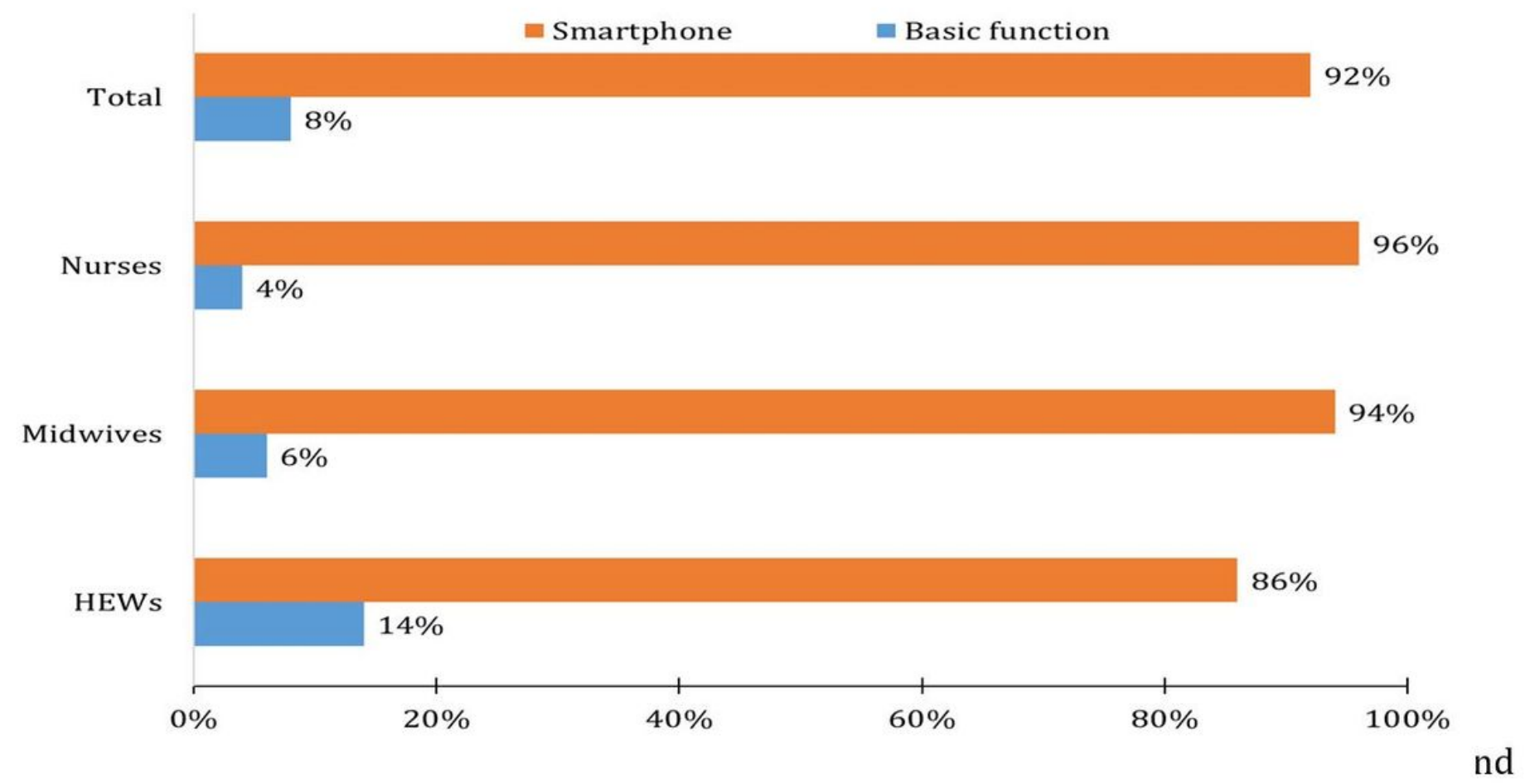

\section{Figure 1}

Type of mobile devices owned by health extension workers, midwives, and nurses, Ethiopia, 2021. 


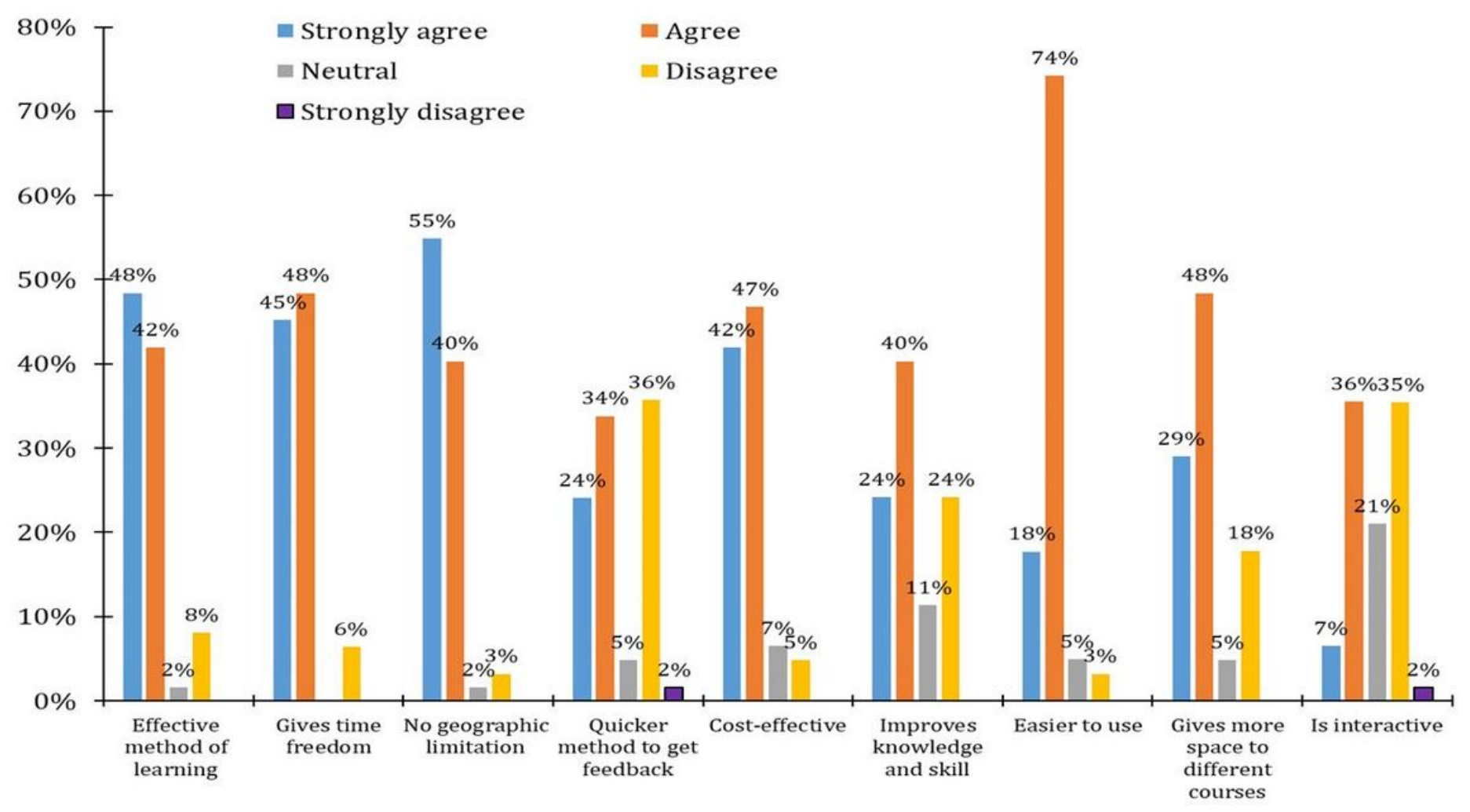

Figure 2

Perception of health extension workers, midwives, and nurses about digital learning as compared to faceto-face learning methods, Ethiopia, 2021. 